\title{
The Modal Analysis of Turbine Rotor Based on Application of ANSYS Software
}

\author{
Wenya Li ${ }^{a}$, Yan Zheng ${ }^{b}$ \\ Henan Vocational College of Agriculture, Zhengzhou 451450, China \\ awenylee@163.com, b15617754@qq.com
}

Keywords: Modal analysis, ANSYS, Finite element model, Turbine Rotor.

\begin{abstract}
As the basis of dynamic analysis, modal analysis can be used to determine the vibration characteristics of mechanical institutions themselves, briefly expounds the basic principle of modal analysis and modal analysis under the environment of ANSYS, and the steps, and a specific example, for turbine rotor calculation of modal analysis shows that the method of modal analysis in ANSYS software, the results show that this method for determine the vibration characteristics of the mechanical structure works, can fully meet the requirements of structural design.
\end{abstract}

\section{Introduction}

Turbocharger is one of the energy will flow into mechanical work of rotating machinery, in fact, a kind of air compressors, compressed air to increase the volume. It is the use of engine exhaust from inertial force to push the turbine indoor turbine, turbine and drive the coaxial impeller, the impeller pressure to send by air filter pipe sent by air, pressurized into the cylinder. When the engine speed increases, exhaust gas discharge speed and turbine speed synchronization also increase, the impeller to compress more air into the cylinder, air pressure and density increase to burn more fuel, a corresponding increase in fuel quantity and adjust the rotating speed of engine, can increase the output power of engine [1]. At present it has been widely used in aviation engine, gas turbine and steam turbine, gas turbine rotor as an important part of turbocharger, its stability and reliability directly affects the quality of the products, has been the general scholars' research focus and direction.

Modal analysis can be used to determine the vibration characteristics of the mechanical structure, have the same frequency and vibration mode, thus in the process of the mechanical structure of the work not the accident caused by vibration, so the modal analysis for the structure design is an integral part of, the result can explain not only the mechanical stiffness of the structure, but also for other dynamics analysis and the basis for vibration fault diagnosis.

\section{The technology of modal analysis}

Modal analysis technology is from the Angle of dynamics analysis of component parts, the method of main is to ensure that the parts assembled into the frequency of the overall size, is able to identify the modal parameters of the whole system, to ensure the structure vibration characteristics, is a kind of systematic discrimination method, can to fault early warning, reduce unnecessary accidents, optimize the structure design, on the whole length of service of the engineering equipment has been greatly promoted [2-3]. The modal analysis technology is mainly for the movement of the turbine rotor system in engineering, has always been more applicable in the field of the whole project.

The principles of its main steps as follows: the first step can take advantage of the matrix transformation method, establish the movement differential equation as shown in formula one, which $\mathrm{M}, \mathrm{C}$ and $\mathrm{K}$ represent the mass, damping, and stiffness in the process of the whole system [4]:

$\mathrm{MX}+\mathrm{CX}+\mathrm{KX}=\mathrm{F}$

In the above formula contains the physical impact of each coordinate, this kind of equation has coupling, solving the difficult, so to the Laplace transform, get as shown in the formula 2: 


$$
\left(\mathrm{s}^{2} \mathrm{M}+\mathrm{sC}+\mathrm{K}\right) \mathrm{X}(\mathrm{s})=\mathrm{F}(\mathrm{s})
$$

In turn, it can get its further transfer function as shown in formula 3:

$$
\mathrm{H}(s)=\frac{X(s)}{F(s)}=\left(s^{2} M+s C+K\right)^{-1}
$$

Therefore, the function matrix of Fourier domain of frequency response is concluded, $w$ is the system's inherent frequency.

$$
H(s)=\left(K-w^{2} M+j w C\right)^{-1}
$$

The equation of motion of the system is:

$$
\left(K-w^{2} M+j w C\right) X(w)=F(w)
$$

After the above few steps, the frequency of the turbine rotor can be calculated.

\section{The modal analysis method based on ANSYS software}

ANSYS software is relatively mature finite element software at the current application, mainly including three parts: 1) pretreatment module; 2) Analysis and calculation module, including structure analysis; 3) Post-processing module [5-6].

ANSYS finite element analysis process involves four steps:

Model: specify the project name and the analysis of the title, and then defined in pretreatment unit type, unit real constant geometric properties, material properties and model;

Loading and solving: define the type of analysis and analysis options, applied load, the natural frequency of the finite element calculation, the only effective in modal analysis of load is zero displacement constraints;

Extension mode: the mode into the resulting file, only after extension mode can see in the post-processing modes;

Post-processing: after expansion mode, the modal analysis results including natural frequency, extension, modal vibration mode, and stress and force distribution will be written to the file structure analysis results.

Among them, the structure model simplification is one of the important steps in finite element analysis. Here, the simplified model is often need to follow two principles: the first is to be able to accurately reflect the real structure of the mechanical characteristics, reasonable calculation structure; Second, try to simplify the model, reduce the complexity of solid model, save computer resource and computing time. Because the actual mechanical structure tend to be more complex, so need to meet the mechanical properties, computing precision and computing time under the condition of the turbine rotor model simplification, before for grid division, according to the turbine rotor structure, bearing characteristics of the turbine rotor model to simplify the structure of some of the details.

By CATIA 3 d software based turbine rotor structure simplified model, the ANSYS Workbench cannot directly save the model of the $3 \mathrm{~d}$ software to read data, should be turbine rotor model file save as STP format. In addition to need to need to use the optimization module in the ANSYS Workbench line data optimization model, because of the imported from outside $3 \mathrm{~d}$ software is used to identify the parameters of model can't, need to create a model in the DM module of ANSYS Workbench, and the optimized structure parameters Settings. Save for CATIA, the $3 \mathrm{~d}$ model. The STP format clear expression of the geometric boundary in the ANSYS, the fault-tolerant model of ANSYS technology can make the data seamlessly.

\section{The modal analysis of turbine rotor}

This paper adopted the 3D modeling build in CATIA. And then import igs format file to the ANSYS Workbench, the Workbench of the model unit type choice: density is $7800 \mathrm{~kg} / \mathrm{m} 3$, modulus of elasticity is 2.0 e11 Pa, poisson ratio is 0.27 , the grid size is $2.0 \mathrm{~mm}$, free meshing. Result is shown in figure 2. 

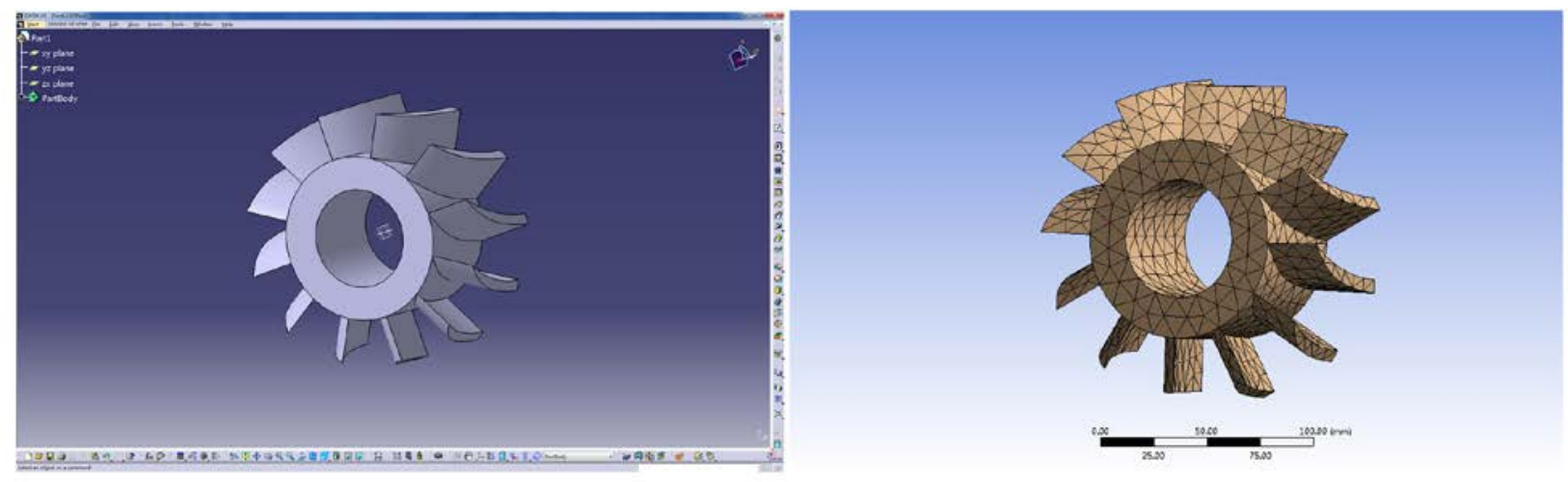

Figure 2. Pretreatment of the turbine rotor

Turbine rotor structure's vibration can be expressed as a linear combination of the each order natural vibration mode and the low order natural vibration type higher order effect on the vibration of the structure is larger, low-order modal dynamic characteristics of the turbine rotor structure plays a very important role, therefore, when doing analysis and calculation of structure vibration characteristics usually take former 4 order. Therefore, this paper calculated the turbine rotor of the 4 order natural frequency and vibration model. The deformation form of turbine rotor at each mode is shown in figure 3:
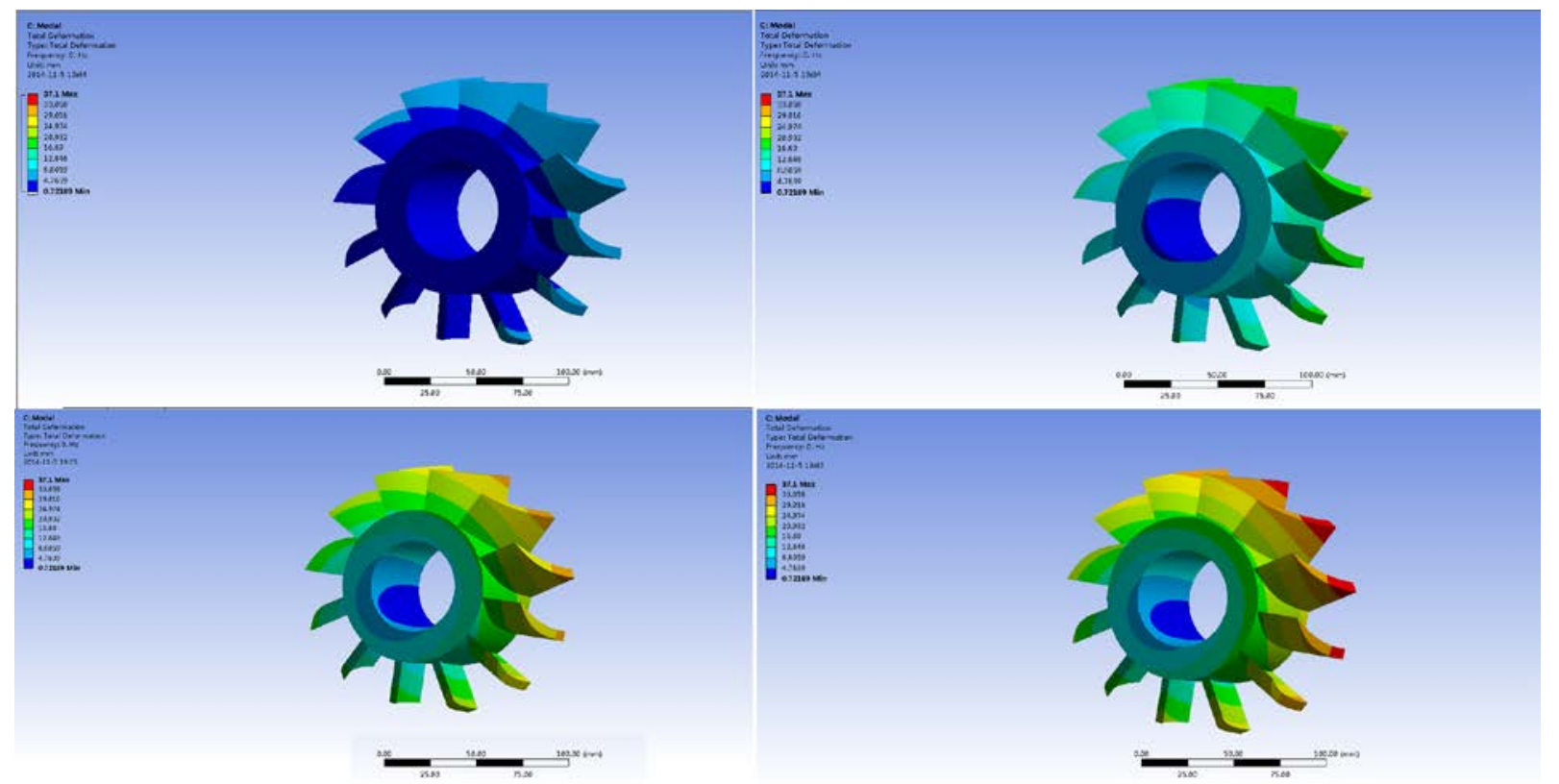

Figure 3. Deformation form of turbine rotor at each mode

This paper puts forward the turbine rotor of machine tool modal analysis technology. It can be presented from the experiment, the method can improve the level of the design of the turbine rotor, the dynamic characteristics of the whole turbine rotor to make a complete and detailed analysis, a scientific reference for further improvement of machine tool.

\section{Conclusion}

Turbine rotor is an important part of turbocharger, its stability and reliability directly affects the quality of the products, has been the general scholars' research focus and direction. In order to ensure work safety and improve service life of the structure of turbine rotor, the modal analysis is necessary. By using CATIA software established the 3D model of the turbine rotor, and the finite element modal analysis for turbine rotor has been carried on, the natural frequency of the turbine rotor and the 
corresponding modal vibration mode are beg out. Using ANSYS software was carried out on the structure modal analysis' method is very simple, not only the calculation speed is very fast, right to establish the calculation model and the unit type appropriate choice, on the basis of its can fully guarantee the accuracy of the calculation results, to determine the mechanical structure of the vibration characteristic, this method is an effective method.

\section{Reference}

[1]. Borden A R, Lesieutre B C, Gronquist J. Power system modal analysis tool developed for industry use[C]//North American Power Symposium (NAPS), 2013. IEEE, 2013: 1-6

[2].Sturmberg B C P, Dossou K B, Botten L C, et al. Modal analysis of enhanced absorption in silicon nanowire arrays[J]. Optics Express, 2011, 19(105): A1067-A1081.

[3].Kocabaş Ş E, Veronis G, Miller D A B, et al. Modal analysis and coupling in metal-insulator-metal waveguides[J]. Physical Review B, 2009, 79(3): 035120.

[4].Devriendt C, De Sitter G, Guillaume P. An operational modal analysis approach based on parametrically identified multivariable transmissibilities[J]. Mechanical Systems and Signal Processing, 2010, 24(5): 1250-1259.

[5].Bai B, Zhang L, Guo T, et al. Analysis of dynamic characteristics of the main shaft system in a hydro-turbine based on ANSYS[J]. Procedia Engineering, 2012, 31: 654-658.

[6].Madhavan S, Jain R, Sujatha C, et al. Vibration based damage detection of rotor blades in a gas turbine engine[J]. Engineering Failure Analysis, 2014, 46: 26-39. 